\title{
REGIONAL RETINAL BLOOD FLOW AND VASCULAR AUTOREGULATION
}

\author{
S. M. B. RASSAM, V. PATEL, H. C. CHEN AND E. M. KOHNER \\ London
}

\begin{abstract}
SUMMARY
The temporal retina is larger than the nasal retina and contains the metabolically active fovea. The variation in the distribution of blood between the temporal and nasal retinal circulations was investigated in 15 healthy volunteers, and the autoregulatory capacity of the temporal and nasal circulations was quantitated using $60 \%$ oxygen in the inspired air. Retinal blood flow was determined from red cell velocity using laser Doppler velocimetry and retinal vessel diameter from retinal photographs using a digital image analysis system. Volume flow was lower in the nasal than the temporal circulation by $52.49 \%(p<0.001)$. This is a consequence of both significantly smaller vessels $(20.4 \%, p<0.001)$ and slower blood velocity in the nasal circulation $(24.64 \%, p=0.003)$ compared with the temporal vessels. After breathing $60 \%$ oxygen for 10 minutes, there was significant vasoconstriction (temporal, $10.42 \pm 1.24 \%$, $p<0.001$; nasal, $7.66 \pm 1.48 \%, p<0.001$ ), slower red cell velocity (temporal, $27.10 \pm 3.92 \%, p<0.001$; nasal, $27.36 \pm 5.51 \%, p<0.001)$ and a significant reduction in the volumetric flow rate (temporal, $41.16 \pm 3.64 \%$, $p<0.001$; nasal, $37.99 \pm 5.07 \%, p<0.001)$. The reduction in the haemodynamic parameters was comparable in the temporal and nasal circulations, indicating similar autoregulatory capacity. Retinal vascular conductance was calculated from volume flow and retinal perfusion pressure. It was $53 \%$ larger in the temporal than the nasal circulations. This provides an index of the metabolic needs of the different regions of the retina.
\end{abstract}

The retinal vessels are the main source of oxygen delivery to the inner retina. ${ }^{1}$ Previous studies have shown retinal blood flow to be higher in the temporal than nasal retinae., ${ }^{2,3}$ This was explained by the facts that the temporal retina is both larger than the nasal retina and contains the metabolically active macula. ${ }^{4,5}$

From: The Diabetic Retinopathy Unit, R.P.M.S., Hammersmith Hospital, London, UK.

Correspondence to: Professor E. M. Kohner, The Diabetic Retinopathy Unit, Department of Medicine, R.P.M.S., Hammersmith Hospital, Du Cane Road, London W12 0NN, UK.
Oxygen has always been known to be a vital element in the metabolism of tissues. Because the retina has a high metabolic activity and requires more oxygen per gram of tissue than any other tissue in the body, ${ }^{6}$ the concentration of oxygen needs to be maintained at relatively stable levels. Cusick and associates ${ }^{7}$ first reported in 1940 that retinal vessels constrict at high oxygen tensions, signifying autoregulation. Oxygeninduced autoregulation caused controversy since the definition of autoregulation did not include changes other than that of perfusion pressure, ${ }^{8}$ until Guyton et al. ${ }^{9}$ expanded the definition to include local metabolites including oxygen. The lack of functional sympathetic innervation to the human retinal vessels makes metabolic autoregulation essential. ${ }^{10}$ Evidence for this comes from the work of Dollery et $a l .{ }^{11}$ who found that vasoconstriction of the retinal vessels in response to oxygen was unaffected by stellate block or thoracic sympathectomy. Also, Alm and Bill, ${ }^{12}$ in their excellent work, found that preretinal oxygen tension was maintained constant in cats despite a reduction in perfusion pressure of the eye from $130 \mathrm{mmHg}$ to $50 \mathrm{mmHg}$. They concluded that oxygen tension is a fundamental stimulus and therefore maintained over a relatively wide range of perfusion pressures. ${ }^{12}$

No distinction has yet been made between the regulatory mechanisms of the temporal retina and the nasal retina; in view of the high metabolic activity of the macula supplied by the temporal vasculature, the autoregulatory response may selectively control flow to the macula more than to the rest of the retina. ${ }^{13}$ To test this hypothesis, retinal haemodynamic measurements were performed on both the temporal and nasal circulations before and after breathing oxygen.

\section{Study Subjects}

\section{METHODOLOGY}

Fifteen healthy volunteers were recruited, age range 20-60 years (mean $\pm S D, 38.53 \pm 10.34$ years). All 
subjects had a normal physical examination, visual acuity of $6 / 12$ or better, normal ocular examination and normal intraocular pressures. Informed consent was obtained from the study subjects after a full detailed explanation of the protocol. Approval from the local ethics committee was granted in accordance with the principles laid down by the Declaration of Helsinki.

\section{Systemic $\mathrm{pO}_{2}$ and $\mathrm{pCO}_{2}$ Changes}

To study the normal metabolic autoregulation of the retinal circulation to oxygen, local oxygen tension in the retinal tissue was increased using $60 \%$ oxygen in the inspired air. This level of oxygen was chosen since it is within the autoregulatory range of the retina. ${ }^{14}$ The $60 \%$ oxygen in the inspired air was achieved using an MCO-1 disposable oxygen mask (Henleys Medical Supplies, Herts, UK). Working on the Venturi principle this mask delivers a relatively accurate percentage of oxygen in the inspired air by controlling the rate of flow of air mixed with the oxygen.

A separate study was performed on 7 of the subjects to determine the systemic changes in the partial pressure of oxygen $\left(\mathrm{pO}_{2}\right)$ and carbon dioxide $\left(\mathrm{pCO}_{2}\right)$ during the inhalation of $60 \%$ oxygen, and also to quantitate the time it takes for these changes to stabilise. The subjects were connected to a transcutaneous $\mathrm{pO}_{2}$ and $\mathrm{pCO}_{2} \mathrm{TC} 100$ monitor (Radiometer, Copenhagen) and were allowed to breath $60 \%$ oxygen through an MCO-1 disposable oxygen mask. Baseline and final $\mathrm{pO}_{2}$ and $\mathrm{pCO}_{2}$ levels were noted and the time it took to achieve the equilibrium.

The average time taken for stabilisation of arterial $\mathrm{pO}_{2}$ was less than 10 minutes (see below). Therefore, it was decided from the outset of the study to use $60 \%$ oxygen in the inspired air for 10 minutes, allowing for this equilibrium, before any retinal haemodynamic measurements were performed.

\section{Study Design}

Pupillary dilatation was achieved with tropicamide $1 \%$ (Minims, Smith \& Nephew, Romford, UK), after which the subjects were allowed to rest for a period of 30 minutes. Blood pressure, pulse and intraocular pressure measurements were taken and retinal haemodynamic studies were performed. These included laser Doppler velocimetry and monochromatic retinal photography (see below). The subjects were then made to breathe $60 \%$ oxygen for 10 minutes prior to repeating laser Doppler velocimetry and retinal photography.

\section{Blood Velocity Measurement}

Retinal blood flow was determined from red cell velocity using bidirectional laser Doppler velocime- try (Oculix, Philadelphia, USA). ${ }^{15}$ This technique utilises the shift in frequency produced when a monochromatic laser beam from a helium-neon laser $\left(632.8 \mathrm{~nm}\right.$, irradiance $\left.80 \mathrm{~mW} / \mathrm{cm}^{2}\right)$ is reflected from moving red blood cells in the retinal vessels. This shift in frequency is directly proportional to the red cell velocity. The frequency-shifted light is collected by a pair of photoreceptors and stored on the hard disc of a minicomputer (Masscomp, Mass., USA); the collected data were analysed later in a randomised masked fashion. Since flow of blood in a vessel is parabolic, ${ }^{16}$ only the maximally shifted frequency was used, representing the maximal centreline red cell velocity $\left(V_{\max }\right)$.

\section{Vessel Diameter Measurement}

Vessel diameter $(D)$ was determined from monochromatic fundus photographs. The photographs were taken with a $30^{\circ}$ Zeiss fundus camera (Carl Zeiss, Oberkochen, Germany) linked to an electrocardiographic monitor through a time-delay device. This device triggered the shutter of the camera at a predetermined point from the electrocardiographic $\mathrm{R}$-wave, and thus allowed all the fundus photographs to be taken in mid-diastole. This technique eliminates the effect of pulsatility on the variation in vessel diameter measurements. ${ }^{17}$ The film used was Kodak Technical Pan film (Kodak, Rochester, NY, USA) and the photographs were taken through a red-free $570 \mathrm{~nm}$ interference filter to enhance the resolution of the vasculature. ${ }^{18}$ The fundus photographs were projected through a video camera, digitised by an image analysis computer (Context Vision, Linköping, Sweden) and projected on a $512 \times 512$ pixel monitor. From the images, retinal vessel diameters were determined using the welldocumented method of the half-height of the transmittance profiles. ${ }^{19}$ Vessel diameter measurements were corrected for the magnification of the camera and the ocular refraction using tables adopted from the work of Bengtsson and Krakau. ${ }^{20}$ Three photographs were taken at each time point during the study and the three vessel diameter measurements from each of the three photographs were averaged.

\section{Site of Blood Flow Measurement}

Blood flow in the superior and inferior temporal veins is similar, as shown by Feke et al. ${ }^{3}$ and Riva et $a l^{2}$ using the laser Doppler technique. Therefore, either the superior or the inferior temporal veins were chosen to measure retinal blood flow, within one disc diameter from the disc edge before any bifurcation. Venous flow was chosen rather than arterial flow because of the limitations of the instrumentation. ${ }^{3}$ Flow in retinal veins has been shown to be similar to that of the corresponding 
Table I. Basic clinical parameters of the study subjects (mean $\pm \mathrm{SD})$

\begin{tabular}{lr}
\hline Age (years) & $38.53 \pm 10.34$ \\
Pulse (beats/min) & $73.14 \pm 13.53$ \\
Systolic blood pressure (mmHg) & $122.9 \pm 10.50$ \\
Diastolic blood pressure $(\mathrm{mmHg})$ & $80.30 \pm 6.80$ \\
Mean arterial blood pressure $(\mathrm{mmHg})$ & $95.32 \pm 7.47$ \\
Intra-ocular pressure $(\mathrm{mmHg})$ & $15.73 \pm 2.52$ \\
Perfusion pressure $(\mathrm{mmHg})$ & $47.81 \pm 5.46$ \\
\hline
\end{tabular}

retinal arteries, adhering to the theory of conservation, since the retinal circulation lacks lymphatic flow. ${ }^{2,3}$

A Polaroid fundus photograph was obtained to mark the exact position of the velocity measurement on the vein. This later provided a reference point for the site of vessel diameter determination.

\section{Volumetric Flow Rate}

The volumetric flow rate $(Q)$ was calculated by multiplying the mean red cell velocity $\left(V_{\text {mean }}\right)$ by the cross-sectional area $(A)$ of the vessel $\left(Q=V_{\text {mean }} \cdot A\right)$. To determine the mean red cell velocity, the maximal centreline red cell velocity $\left(V_{\max }\right)$ was divided by a factor of 1.6 according to the work of Baker and Wayland ${ }^{16}$ and Damon and Duling, ${ }^{21}$ since blood does not flow like a perfect Newtonian fluid. The cross-sectional area of the vessel was determined from vessel diameter $(D)$. The formula to calculate the flow therefore becomes:

$$
Q=\frac{V_{\max }}{1.6} \cdot \frac{\pi \cdot D^{2}}{4}
$$

\section{Retinal Perfusion Pressure}

Blood pressure was determined using a Takeda automated digital blood pressure meter (A\&D Engineering, Calif., USA) calibrated with a random zero mercury sphygmomanometer (Hawksley \& Sons, UK). Intraocular pressure was measured with Goldmann applanation tonometry. Mean arterial blood pressure (MAP) was calculated by adding the diastolic blood pressure $\left(\mathrm{BP}_{\mathrm{D}}\right)$ to one-third the difference between the systolic $\left(\mathrm{BP}_{\mathrm{S}}\right)$ and diastolic blood pressures $\left(\mathrm{MAP}=1 / 3\left[\mathrm{BP}_{\mathrm{S}}-\mathrm{BP}_{\mathrm{D}}\right]+\mathrm{BP}_{\mathrm{D}}\right)$. Perfusion pressure (PP) was determined by subtracting the intraocular pressure (IOP) from two-thirds the mean arterial blood pressure $(\mathrm{PP}=2 / 3 \mathrm{MAP}$ $-\mathrm{IOP}){ }^{13}$

\section{Retinal Vascular Conductance}

From the values of retinal volume flow and ocular
Table III. Results of transcutaneous measurements of systemic partial pressure of oxygen $\left(\mathrm{pO}_{2}\right)$ and systemic partial pressure of carbon dioxide $\left(\mathrm{pCO}_{2}\right)$ before and after breathing $60 \%$ oxygen for 10 minutes

\begin{tabular}{lcc}
\hline & $\mathrm{pO}_{2}$ & $\mathrm{pCO}_{2}$ \\
\hline Baseline (mmHg) & $7.70 \pm 2.36$ & $5.10 \pm 0.76$ \\
Mean $\pm \mathrm{SD}$ & 4.00 to 11.60 & $\mathrm{~N} / \mathrm{A}$ \\
Range & $25.70 \pm 7.05$ & $5.00 \pm 0.69$ \\
Maximal level (mmHg) & 16.20 to 35.00 & N/A \\
Mean $\pm \mathrm{SD}$ & $7.86 \pm 1.03$ & N/A \\
Range &
\end{tabular}

perfusion pressures determined, conductance $(\mu \mathrm{l} /$ $\mathrm{min} / \mathrm{mmHg}$ ) of the retinal vessels was calculated. This is retinal blood flow per unit of perfusion pressure and is calculated by dividing retinal volume blood flow by the perfusion pressure. ${ }^{22}$

\section{STATISTICAL ANALYSIS}

Results are expressed as mean \pm SEM except where otherwise stated. One-way analysis of variance (ANOVA) was used initially to determine whether significant differences existed. If significant differences were found Student's $t$-test was applied (Oxstat II, Microsoft, 1985). Retinal haemodynamics between the temporal and nasal circulations were compared using an unpaired Student's $t$-test. Changes in retinal haemodynamics after breathing oxygen were compared with baseline data using a paired Student's $t$-test. Results were considered to be statistically significant when $p \leqslant 0.05$.

\section{RESULTS}

The basic clinical parameters of the study subjects are summarised in Table I. Haemodynamic data for temporal and nasal vessels are summarised in Table II.

\section{Systemic $\mathrm{pO}_{2}$ and $\mathrm{pCO}_{2}$ Changes}

The rise in $\mathrm{pO}_{2}$ was $233.8 \%$ on average while the $\mathrm{pCO}_{2}$ did not show any significant change during oxygen breathing. The average time taken for stabilisation of arterial $\mathrm{pO}_{2}$ was 7.86 minutes (Table III).

\section{Haemodynamic Parameters Before Oxygen}

It is apparent that the nasal vessels are significantly smaller than the temporal vessels by $20.4 \%$ $(p<0.001)$. The velocity of red cells is slower in the nasal vessels by $24.64 \%$ relative to their velocity in the temporal vessels $(p=0.003)$. The volumetric flow

Table II. Haemodynamic parameters before and after breathing oxygen (mean \pm SEM)

\begin{tabular}{|c|c|c|c|c|}
\hline \multirow[b]{3}{*}{ Vessel diameter $(\mu \mathrm{m})$} & \multicolumn{2}{|c|}{ Temporal } & \multicolumn{2}{|c|}{ Nasal } \\
\hline & Pre- $\mathrm{O}_{2}$ & Post- $\mathrm{O}_{2}$ & Pre- $\mathrm{O}_{2}$ & Post- $\mathrm{O}_{2}$ \\
\hline & $158.63 \pm 5.37$ & $142.15 \pm 5.30$ & $126.27 \pm 4.93$ & $116.60 \pm 5.05$ \\
\hline Red cell velocity $(\mathrm{cm} / \mathrm{s})$ & $2.07 \pm 0.11$ & $1.51 \pm 0.12$ & $1.56 \pm 0.11$ & $1.16 \pm 0.12$ \\
\hline Blood flow $(\mu \mathrm{l} / \mathrm{min})$ & $15.47 \pm 1.24$ & $9.00 \pm 0.84$ & $7.35 \pm 0.66$ & $4.70 \pm 0.63$ \\
\hline Conductance $(\mu \mathrm{l} / \mathrm{min} / \mathrm{mmHg})$ & $0.331 \pm 0.031$ & $0.193 \pm 0.021$ & $0.156 \pm 0.014$ & $0.009 \pm 0.013$ \\
\hline
\end{tabular}




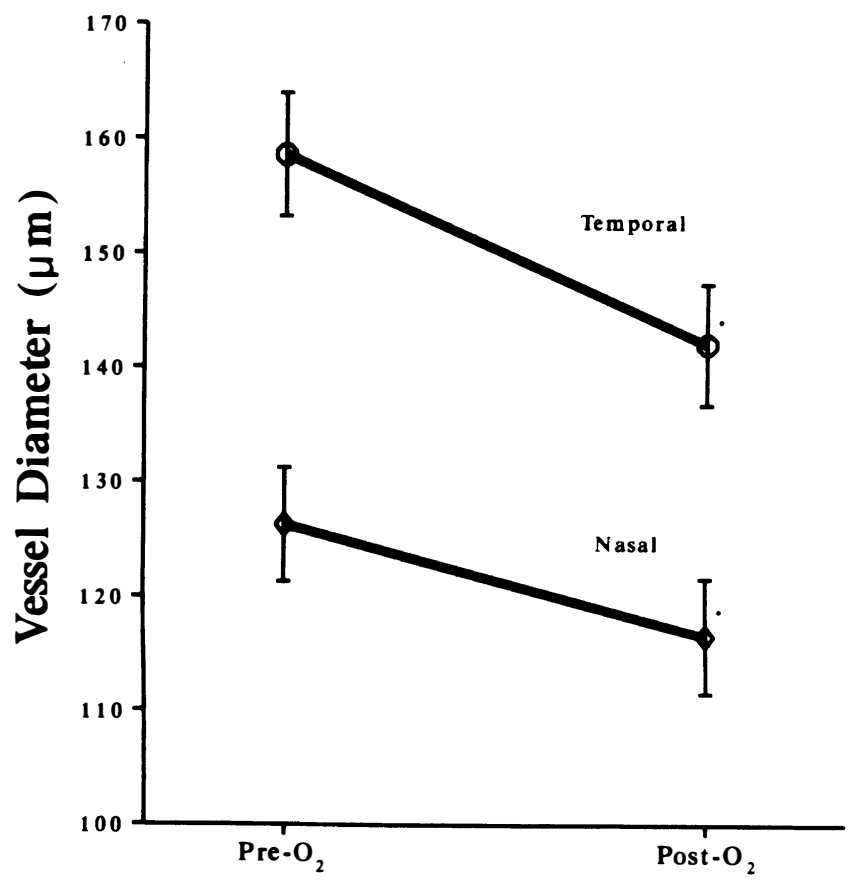

Fig. 1. Retinal vessel diameters before and after breathing oxygen. Results are expressed as mean $\pm S E M .{ }^{*} \mathrm{p}<0.001$ in comparison with pre-oxygen data.

rate is lower in the nasal than the temporal circulations by $52.49 \% \quad(p<0.001)$. Conductance value of the nasal circulation is significantly smaller $(p<0.001)$ and almost half that of the temporal circulation $(52.87 \%)$.

\section{Haemodynamic Parameters after Oxygen}

There was significant vasoconstriction in the temporal circulation by $10.42 \pm 1.24 \% \quad(p<0.001)$ and in

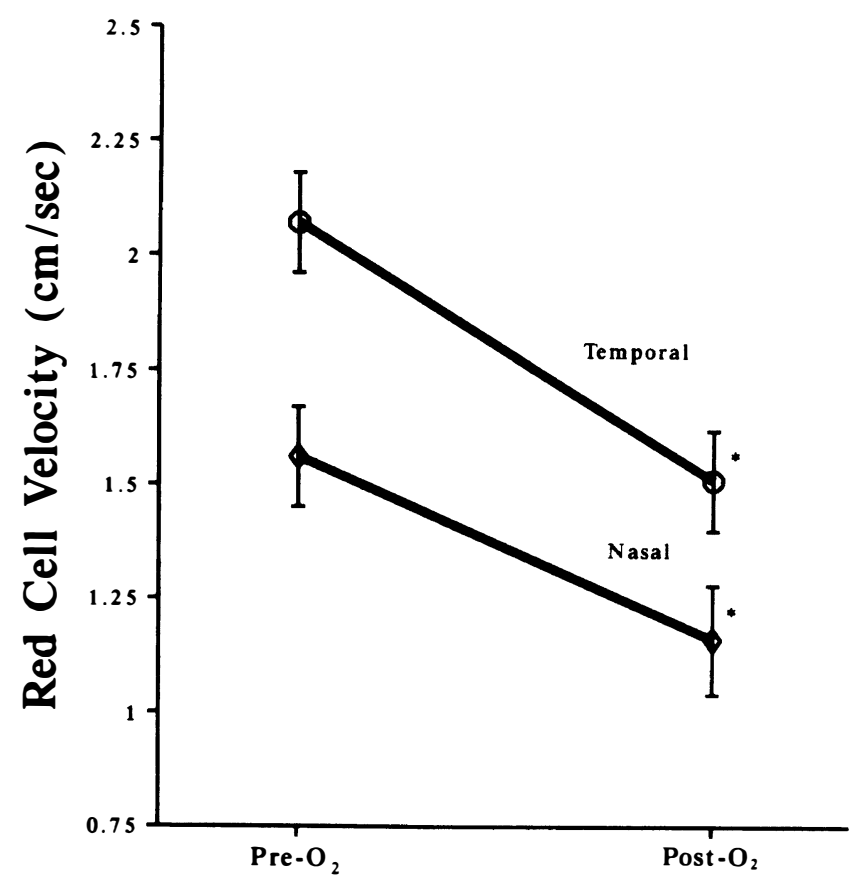

Fig. 2. Retinal blood velocity before and after breathing oxygen. Results are expressed as mean \pm SEM. ${ }^{*} \mathrm{p}<0.001$ in comparison with pre-oxygen data.

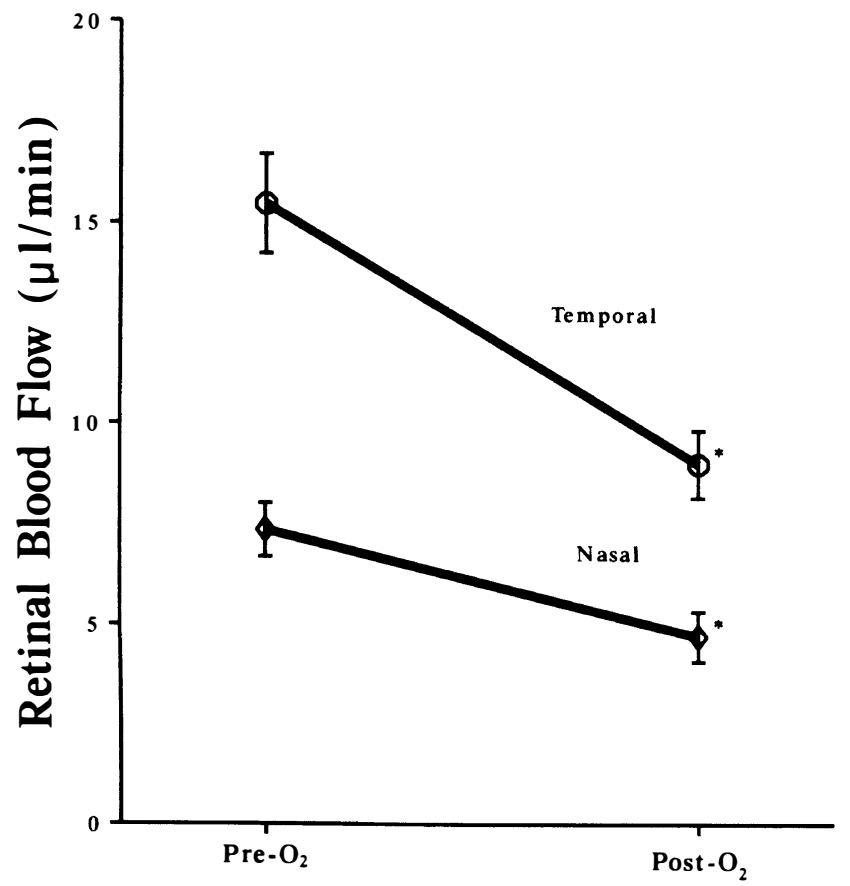

Fig. 3. Retinal blood flow before and after breathing oxygen. Results are expressed as mean $\pm S E M .{ }^{*} \mathrm{p}<0.001$ in comparison with pre-oxygen data.

the nasal circulation by $7.66 \pm 1.48 \%(p<0.001)$ after breathing $60 \%$ oxygen for 10 minutes (Fig. 1). No significant difference was found in the amount of vasoconstriction between the temporal and nasal circulations. A comparable and significant reduction in red cell velocity in the temporal $(27.10 \pm 3.92 \%)$ and nasal $(27.36 \pm 5.51 \%)$ circulations $(p<0.001)$ was seen (Fig. 2). The reduction in retinal blood flow was significant $(p<0.001)$ and comparable in both the temporal $(41.16 \pm 3.64 \%)$ and nasal $(37.99 \pm 5.07 \%)$ circulations (Fig. 3). A significant and comparable reduction in the conductance values of both the temporal $(41.16 \pm 3.64 \%)$ and nasal $(37.99 \pm 3.64 \%)$ circulations was seen after breathing $60 \%$ oxygen $(p<0.001)$ in comparison with baseline (Fig. 4).

No change in the systolic and diastolic blood pressures was noted during oxygen breathing.

\section{DISCUSSION}

This study quantitates retinal blood flow and vascular metabolic autoregulation to $60 \%$ oxygen. It also delineates the difference between the temporal and nasal circulations.

Breathing $60 \%$ oxygen using an MCO-1 mask produced a significant rise in systemic $\mathrm{pO}_{2}$ without any change in the $\mathrm{pCO}_{2}$. This is important since, theoretically, the hyperoxia produced may induce respiratory depression leading to a concurrent hypercapnia. ${ }^{23}$ Carbon dioxide is known to have a more potent effect on retinal autoregulatory mechanisms than oxygen. ${ }^{24}$ Therefore this technique allowed the study of the effect of hyperoxia alone without the influence of carbon dioxide. 


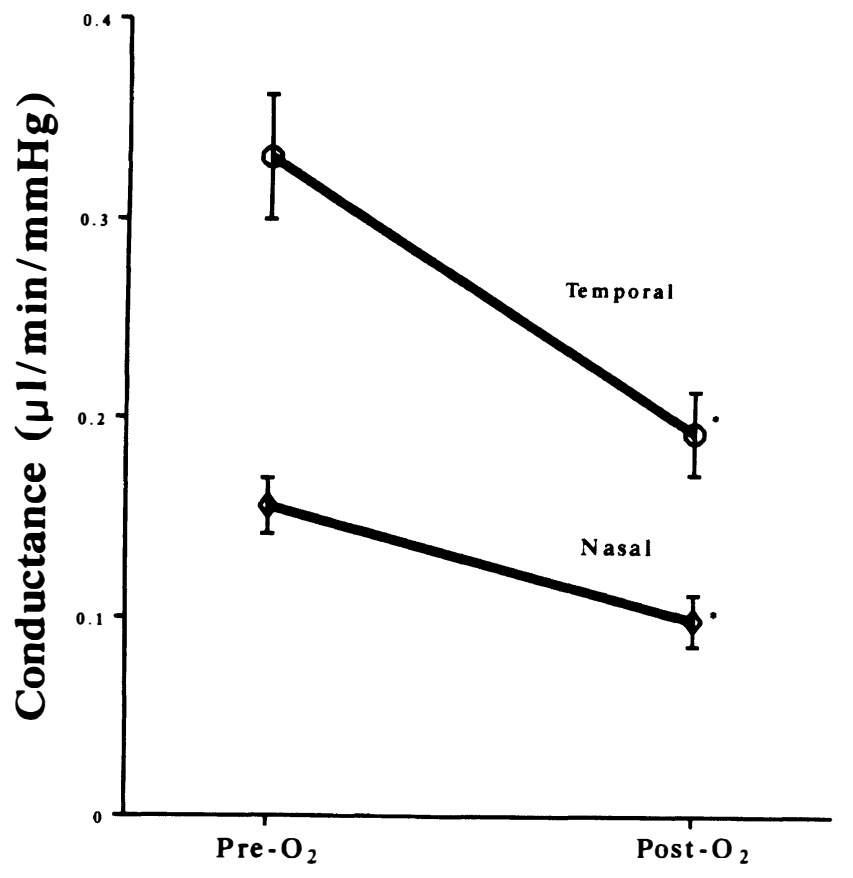

Fig. 4. Retinal vascular conductance before and after breathing oxygen. Results are expressed as mean \pm SEM. ${ }^{*} \mathrm{p}<0.001$ in comparison with pre-oxygen data.

In this study, blood velocity was faster in the temporal circulation by $24.64 \%$. This is comparable to the difference of $27 \%$ documented by Oberhoff $e t$ $a .^{25}$ in 1965, using fluorescein transit time. The difference in the volumetric flow rate found in our study $(52.49 \%)$ is not far off that recorded by Riva et $a l^{2}$ in 1986 , who found $45 \%$ higher flow in the temporal than the nasal veins, measured by laser Doppler velocimetry and projection micrometry in 12 healthy volunteers. Riva et al. found that this difference in flow correlates significantly with the difference in temporal and nasal vascular crosssectional area. On the other hand Feke et al. ${ }^{3}$ in 1989, using a similar technique in 10 healthy volunteers, found $65 \%$ higher flow in the temporal than the nasal retina. Using labelled microspheres, Alm and Bill ${ }^{4}$ in 1973 showed that the macular blood flow was 4 times larger than the flow in the intermediate and peripheral retina. Therefore, the higher flow rate in the temporal circulation may be explained by the fact that the temporal retina has $20-25 \%$ more tissue than the nasal retina. ${ }^{4,5}$

The conductance of a circulation is used as a measure of its ability to allow blood flow through at a given perfusion pressure, thus providing an index of the metabolic needs of the retina independent of changes in perfusion pressure. To our knowledge, no study has looked at this index in the retina previously. In this study, conductance of the temporal circulation was $52.87 \%$ larger than that of the nasal circulation. This indicates that at a given perfusion pressure, flow in the temporal retina is twice as large as that in the nasal retina. However, the temporal retina is only $20-25 \%$ larger than the nasal retina. ${ }^{4,5}$ This means that a gram of tissue in the temporal retina is supplied by more blood than a gram of tissue in the nasal retina. This may reflect the high metabolic need of the macula.

Breathing $60 \%$ oxygen in this study produced an average rise in the transcutaneous oxygen tension of $233 \%$ after the 10 minutes. The significant vasoconstriction produced can be interpreted in terms of the explanation given by Dollery et al. ${ }^{26}$ They proposed that during hyperoxia, the retina obtains practically all its oxygen from the choroidal circulation. The retinal vasculature becomes redundant as a supply of oxygen with resultant vasoconstriction. Riva et al. ${ }^{27}$ challenged this viewpoint by demonstrating a higher pre-retinal $\mathrm{pO}_{2}$ tension in comparison with the $\mathrm{pO}_{2}$ in an area of retina adjacent to the choroid. Also the rise in $\mathrm{pO}_{2}$ in the periarterial area of the retinal vessels preceded the decrease in retinal blood flow, indicating an autoregulatory response of the retinal circulation to hyperoxia.

Most of the literature on retinal haemodynamics is concerned with the temporal circulation. Therefore, for the purpose of comparing the autoregulatory changes in our study with other studies in the literature, the temporal circulation is referred to in this section. A reduction in blood velocity of $27.05 \%$ and a decrease in vessel diameter of $10.39 \%$ in our study are in close agreement with the findings of the only other study that used $60 \%$ oxygen in the inspired air by Fallon et al. ${ }^{28} \mathrm{He}$ found a $36 \%$ decrease in macular blood velocity and a $10 \%$ decrease in temporal retinal vein diameter in response to breathing $60 \%$ oxygen using the blue field entoptic phenomenon and fundus photographs. Previous workers have shown that oxygen levels in the inspired air up to $80 \%$ lie within the autoregulatory range of the retinal circulation. ${ }^{14}$ Levels of more than $80 \%$ oxygen causes a profound rise in vitreal oxygen tension signalling an override of the autoregulatory mechanisms of the retinal circulation. Hickam and Frayser ${ }^{29}$ demonstrated alteration of retinal metabolism when oxygen in the inspired air rose above $60 \%$. For these reasons, $60 \%$ oxygen in the inspired air was chosen rather that $100 \%$. Nevertheless, Hickam et al., using the mean circulation time of fluorescein in normal volunteers, found $14.9 \%$ narrowing in the retinal veins, ${ }^{30}$ a reduction in the velocity of fluorescein by $27 \%^{31}$ and a decrease in retinal blood flow by approximately $57 \%$ after breathing $100 \%$ oxygen. ${ }^{32}$ This is not surprisingly higher than the decrease in retinal blood flow in our study $(41.82 \%)$. Riva et al $^{33}$ found a $64 \%$ reduction in retinal blood flow, $53 \%$ decrease in velocity and $12 \%$ decrease in vessel diameter using laser Doppler velocimetry after breathing $100 \%$ oxygen. Similarly, Grunwald et al. $^{34}$ found a $61 \%$ decrease in retinal 
blood flow in response to $100 \%$ oxygen. All these studies are comparable to each other, but give higher values than our study, as expected from the higher percentage of oxygen in the inspired air.

No other study has looked at retinal vascular autoregulation in different regions of the retina. Because of the higher metabolic activity of the macula, autoregulation to changes in local metabolites is expected to be more strictly controlled in the temporal than the nasal circulations. However, in this study there was no significant difference in the volumetric flow rate after breathing oxygen between the temporal $(41.82 \%)$ and nasal $(36.05 \%)$ circulations. This may be explained by the fact that the extra oxygen demands of the metabolically active macula have already been met by the higher flow in the temporal retina, as discussed above. The increased oxygenation with hyperoxia will, therefore, have the same effect on all parts of the retinal circulation.

In conclusion, the distribution of blood to different parts of the retina seems to be finely tuned according to functional tasks and metabolic needs. The autoregulatory mechanisms then seem to oversee this delicate balance and make the necessary adjustments to blood flow to the retina as a whole in response to any change in its environment.

Key words: Laser Doppler velocimetry, Retinal blood flow, Retinal vascular autoregulation.

\section{REFERENCES}

1. Sakaue H, Negi A, Handa Y. Comparative study of vitreous oxygen tension on human and rabbit eyes. Invest Ophthalmol Vis Sci 1989;30:1933-7.

2. Riva CE, Grunwald JE, Sinclair SH, Petrig BL. Blood velocity and volumetric flow rate in human retinal vessels. Invest Ophthalmol Vis Sci 1985;26:1124-32.

3. Feke GT, Tagawa H, Deupree DM, Goger DG, Sebag $\mathrm{J}$, Weiter JJ. Blood flow in the normal human retina. Invest Ophthalmol Vis Sci 1989;30:58-65.

4. Alm A, Bill A. Ocular and optic nerve blood flow at normal and increased intraocular pressures in monkeys (Macaca irus): a study with radioactively labelled microspheres including flow determinations in brain and some other tissues. Exp Eye Res 1973;15:15-29.

5. Hill DW. The regional distribution of retinal circulation. Ann Coll Surg Eng 1977;59:470-5.

6. Wise GN, Dollery CT, Henkind P. Structure of retinal vessels. In: The retinal circulation. New York: Harper and Row, 1971:34-54.

7. Cusick PL, Benson OO Jr, Boothby WM. Effect of anoxia and of high concentrations of oxygen on the retinal vessels: preliminary report. Proc Mayo Clin 1940;15:500-2.

8. Johnson PC. Autoregulation of intestinal blood flow in the rat. J Physiol (Lond) 1952;123:574.

9. Guyton AC, Ross JM, Carrier O, Walker JR. Evidence for tissue oxygen demand as the major factor causing autoregulation. Circ Res 1954;1(Suppl 14/15):60-9.

10. Alm A. Ocular blood flow. In: Drance SM, editor. International symposium on glaucoma, ocular blood flow and drug treatment. Baltimore: Williams and Wilkins, 1992.
11. Dollery CT, Hill DW, Mailer CM, Ramalho PS. High oxygen pressure and the retinal blood vessels. Lancet 1964;2:291-2.

12. Alm A, Bill A. The oxygen supply to the retina. I. Effects of changes in intraocular and arterial blood pressure, and in arterial $\mathrm{pO}_{2}$ and $\mathrm{pCO}_{2}$ on the oxygen tension in the vitreous body of the cat. Acta Physiol Scand 1972;84:261-74.

13. Grunwald JE, Riva CE, Kozart DM. Retinal circulation during a spontaneous rise of intraocular pressure. Br J Ophthalmol 1988;72:754-8.

14. Yu D, Cringle SJ, Alder VA. The response of the rat vitreal oxygen tension to stepwise increases in inspired percentage oxygen. Invest Ophthalmol Vis Sci 1990;31:2493-9.

15. Feke GT, Goger DG, Tagawa H, Delori FC. Laser Doppler technique for absolute measurement of blood speed in retinal vessels. IEEE Trans Biomed Eng 1987;34:673-80.

16. Baker $\mathrm{M}$, Wayland $\mathrm{H}$. On-line volume flow rate and velocity profile measurement for blood in microvessels. Microvasc Res 1974;7:131-43.

17. Chen HC, Patel V, Wiek J, Rassam SM, Kohner EM. Vessel diameter changes during the cardiac cycle. Eye 1994;8:97-103.

18. Delori FC, Gragoudas ES, Francisco R, Pruett RC, Monochromatic ophthalmoscopy and fundus photography. Arch Ophthalmol 1977;95:861-8.

19. Rassam S, Patel V, Kohner EM. Accurate vessel width measurement from fundus photographs: a new concept. Br J Ophthalmol 1994;78:24-9.

20. Bengtsson B, Krakau CET. Some essential optical features of the Zeiss fundus camera. Acta Ophthalmol (Copenh) 1977;55:123-31.

21. Damon DN, Duling BR. A comparison between mean blood velocities and center-line red cell velocities as measured with a mechanical image streaking velocimeter. Microvasc Res 1979;17:330-2.

22. Ross J, Schmid-Schoenbein G. Dynamics of the peripheral circulation. In: West HM, Taylor R, editors. West and Taylor's physiological basis of medical practice. Baltimore: Williams and Wilkins, 1990:13858.

23. Ganong WF. Respiratory adjustments. In: Review of medical physiology, 9th edn. Los Altos: Lange Medical Publications, 1979: 525-37.

24. Sponsel WE, DePaul KL, Zetlan SR. Retinal hemodynamic effects of carbon dioxide, hyperoxia and mild hypoxia. Invest Ophthalmol Vis Sci 1992;33:1864-9.

25. Oberhoff PA, Evans PY, Delaney JF. Cinematoangiographic documentation of retinal circulation times. Arch Ophthalmol 1965;74:77.

26. Dollery CT, Bulpitt CT, Kohner EM. Oxygen supply to the retina from the retinal and choroidal circulations at normal and increased arterial oxygen tensions. Invest Ophthalmol Vis Sci 1969;8:558-94.

27. Riva CE, Pournaras CJ, Tsacopoulos, M. Regulation of local oxygen tension and blood flow in the inner retina during hyperoxia. J Appl Physiol 1986;61:592-8.

28. Fallon TJ, Maxwell D, Kohner EM. Retinal vascular autoregulation in conditions of hyperoxia and hypoxia using the blue field entoptic phenomenon. Ophthalmology 1985;92:701-5.

29. Hickam JB, Frayser R. Photographic measurement of retinal venous blood oxygen: values in normal subjects and the effect of changes in body position and the inhalation of low and high oxygen mixtures. USAF School of Aerospace Medicine Report 1959;58:155.

30. Hickam JB, Frayser R, Ross JC. A study of retinal 
venous blood oxygen saturation in human subjects by photographic means. Circulation 1963;27:375.

31. Hickam JB, Frayser R. A photographic method for measuring the mean retinal circulation time using fluorescein. Invest Ophthalmol 1965;4:876-84.

32. Hickam JB, Frayser R. Studies of the retinal circulation in man: observations on vessel diameter, arteriovenous oxygen difference and mean circulation time. Circulation 1966;33:302-16.
33. Riva CE, Grunwald JE, Sinclair SH. Laser Doppler velocimetry study of the effect of pure oxygen breathing on retinal blood flow. Invest Ophthalmol Vis Sci $1983 ; 24: 47-51$.

34. Grunwald JE, Riva CE, Brucker AJ, Sinclair SH, Petrig BL. Altered retinal vascular response to $100 \%$ oxygen breathing in diabetes. Ophthalmology 1984;91: $1447-52$ 